\title{
Transcutaneous Electrical Nerve Stimulation on the PC-5 and PC-6 Points Alleviated Hypotension after Epidural Anaesthesia, Depending on the Stimulus Frequency
}

\author{
Young-Chang P. Arai, ${ }^{1,2}$ Akihiro Ito, ${ }^{1}$ Kenji Ohshima, ${ }^{1}$ Soki Hibino, ${ }^{1}$ \\ Sinnosuke Niwa, ${ }^{1}$ Jun Kawanishi, ${ }^{1}$ Hiroki Numanami, ${ }^{1}$ Yoshikazu Sakakima, ${ }^{1}$ \\ Shouji Mizuno, ${ }^{1}$ Yusuke Tawada, ${ }^{1}$ Yuki Maruyama, ${ }^{1}$ Jun Sato, ${ }^{2}$ Makoto Nishihara, \\ Shinsuke Inoue, ${ }^{2}$ and Takahiro Ushida ${ }^{2}$ \\ ${ }^{1}$ Department of Surgery, Toki Municipal General Hospital, Gifu 509-5193, Japan \\ ${ }^{2}$ Multidisciplinary Pain Centre, Aichi Medical University, School of Medicine, 21 Karimata, Nagakutecho, Aichigun, \\ Aichi 480-1195, Japan \\ Correspondence should be addressed to Young-Chang P. Arai, arainon@aichi-med-u.ac.jp
}

Received 13 October 2011; Accepted 27 October 2011

Academic Editor: Gerhard Litscher

Copyright () 2012 Young-Chang P. Arai et al. This is an open access article distributed under the Creative Commons Attribution License, which permits unrestricted use, distribution, and reproduction in any medium, provided the original work is properly cited.

\begin{abstract}
Neuraxial blockade causes arterial hypotension. Transcutaneous electrical nerve stimulation (TENS) at the Neiguan (PC-6) and Jianshi (PC-5) reduces the severity of hypotension after spinal anaesthesia, but did not clarify the optimal stimulus frequency. We hypothesized that the stimulus frequency of TENS at the PC- 6 and PC-5 points would influence the severity of hypotension after epidural anaesthesia. 65 ASA I or II male patients presenting for inguinal hernia repair were randomized to five groups: the control group received no treatment; the $2 \mathrm{~Hz}, 10 \mathrm{~Hz}, 20 \mathrm{~Hz}$, and $40 \mathrm{~Hz}$ groups received TENS at a frequency of $2 \mathrm{~Hz}, 10 \mathrm{~Hz}, 20 \mathrm{~Hz}$, and $40 \mathrm{~Hz}$, respectively. The lowest SBP was significantly higher in the $40 \mathrm{~Hz}$ group [the control, $84(74-110) \mathrm{mmHg}$; the $2 \mathrm{~Hz}, 96$ (62-116) $\mathrm{mmHg}$; the $10 \mathrm{~Hz}, 100(68-110) \mathrm{mmHg}$; the $20 \mathrm{~Hz}, 96(64-115) \mathrm{mmHg}$; the $40 \mathrm{~Hz}, 104$ (75-140) mmHg: $P=0.004]$. Significantly less patients experienced hypotension in the $40 \mathrm{~Hz}$ group [the control, $78 \%$; the $2 \mathrm{~Hz}, 43 \%$; the $10 \mathrm{~Hz}, 38 \%$; the $20 \mathrm{~Hz}, 38 \%$; the $40 \mathrm{~Hz}, 8 \%: P=0.008$ ]. TENS on the PC-6 and PC-5 points reduced the severity and incidence of hypotension after epidural anaesthesia, depending on the stimulus frequency.
\end{abstract}

\section{Introduction}

Neuraxial blockade, epidural anaesthesia, causes arterial and venous vasodilation and decrease in venous return due to blockade of the sympathetic nervous system, which results in arterial hypotension $[1,2]$.

In animal studies, electroacupuncture at the Neiguan (PC-6) and Jianshi (PC-5) points affects the circulatory and sympathetic nervous system $[3,4]$, especially electroacupuncture at the PC-6 point increases haemodynamics [5] and makes bleeding-induced hypotension less severe [6]. Our previous study showed that a frequency of $50 \mathrm{~Hz}$ of transcutaneous electrical nerve stimulation (TENS) at the PC-5 and PC-6 reduces the severity of hypotension after spinal anaesthesia, but did not test the appropriate frequency of electrical stimulation of TENS [7]. However, several studies showed that electroacupuncture evokes pressor or depressor response, depending on the stimulus frequency. That is, the autonomic nervous system might be influenced by the stimulus frequency of TENS.

We thus hypothesized that the stimulus frequency of TENS at the PC- 6 and PC-5 points would affect the activity of the autonomic nervous system, thereby differentially influencing the severity of hypotension after epidural anaesthesia. The purpose of the present study was to test the effect of four different frequencies of TENS at the PC- 5 and PC- 6 points on haemodynamics after epidural anaesthesia in patients undergoing inguinal hernia repair. 
TABle 1: Demographic and anaesthetic data. Data are median (range). Wound-based time: baseline measurements to wound closure time.

\begin{tabular}{|c|c|c|c|c|c|c|}
\hline & Control $(n=14)$ & $2 \mathrm{~Hz}(n=13)$ & $10 \mathrm{~Hz}(n=12)$ & $20 \mathrm{~Hz}(n=13)$ & $40 \mathrm{~Hz}(n=13)$ & $P$ \\
\hline Age (yr) & $69(61-74)$ & $66(43-82)$ & $74.5(49-88)$ & $73(23-84)$ & $69(36-886)$ & 0.442 \\
\hline Height $(\mathrm{cm})$ & $160(148-173)$ & $163(148-175)$ & $159(148-174)$ & $162(150-170)$ & $159(137-179)$ & 0.773 \\
\hline Weight $(\mathrm{kg})$ & $61(50-72)$ & $62(39-76)$ & $57(41-64)$ & $58(45-66)$ & $54(47-94)$ & 0.578 \\
\hline Wound-based time (min) & $45(28-55)$ & $40(28-55)$ & $42(38-46)$ & $42(38-45)$ & $40(35-55)$ & 0.932 \\
\hline
\end{tabular}

\section{Methods}

After obtaining approval from the Ethics Committees of our institutions and written informed patient's consent, 67 ASA I or II male patients presenting for inguinal hernia repair under epidural anaesthesia were enrolled in the present study. Patients suffering from hypertension, diabetes, or obesity were excluded.

Patients were randomized into five groups, using sealed envelopes: the control group received no treatment; the $2 \mathrm{~Hz}$ group received TENS at a frequency of $2 \mathrm{~Hz}$ bilaterally at the PC-5 and PC- 6 points (on the palmar side of both arms, between the tendon of the long palmar muscle and radial flexor muscle of the wrist) $[7,8]$ (Figure 1) by a TENS stimulator (NeuroTrax TENS \& AcuStim; Verity Medical LTD, Hampshire, uk); the $10 \mathrm{~Hz}, 20 \mathrm{~Hz}$, and $40 \mathrm{~Hz}$ groups received TENS at 10,20, and $40 \mathrm{~Hz}$ bilaterally at the PC-5 and PC-6 points by the TENS stimulator, respectively. All patients fasted for a minimum of $6 \mathrm{~h}$ preoperatively. At the operation room, all patients had standard monitoring in place (noninvasive arterial pressure, electrocardiogram (ECG), and pulse oximetry) and these baseline values were recorded. In the $2 \mathrm{~Hz}, 10 \mathrm{~Hz}, 20 \mathrm{~Hz}$, and $40 \mathrm{~Hz}$ groups, then, small-sized $(1.5 \mathrm{~cm})$ cutaneous electrode pads were put bilaterally at the PC- 6 and PC-5 points. The intensity of the electrical stimulation was adjusted to produce the most intense tolerable electrical sensation without muscle contractions at a frequency of 2, 10, 20, or $40 \mathrm{~Hz}$ and a duration of $100 \mu$ s until the end of surgery. After intravenous access, acetated Ringer's solution $\left(10 \mathrm{~mL} \mathrm{~kg}^{-1}\right)$ was administered before the induction of anaesthesia. With the patient on the right side, $10 \mathrm{~mL}$ of $2 \%$ lidocaine was injected after identification of the epidural space at the L1-L2 interspace using a 17-gauge Tuohy needle, and then a 20 -gauge epidural catheter was placed.

The anaesthetic level was measured by pinprick at the right mid-clavicular line every two minutes. Surgery started when an adequate dermatome level of anaesthesia from Th8 to L2 was ensured. In the case of inappropriate cephalad spread of anaesthesia, incremental epidural supplements of $2 \%$ lidocaine were given, starting with $4 \mathrm{~mL}$. When necessary, additional $2 \mathrm{~mL}$ boluses were given no earlier than $5 \mathrm{~min}$ after the preceding top-up. Haemodynamics were recorded every minute for 30 minutes after the injection of $10 \mathrm{~mL}$ of $2 \%$ lidocaine and then every 2.5 minutes until the end of surgery. In the case of hypotension, ephedrine of $4 \mathrm{mg}$ was given intravenously. If necessary, additional ephedrine of $4 \mathrm{mg}$ was given every two minutes. We defined hypotension as a decrease in systolic blood pressure (SBP) 30\% below baseline values or to less than $90 \mathrm{mmHg}$ in the present study.

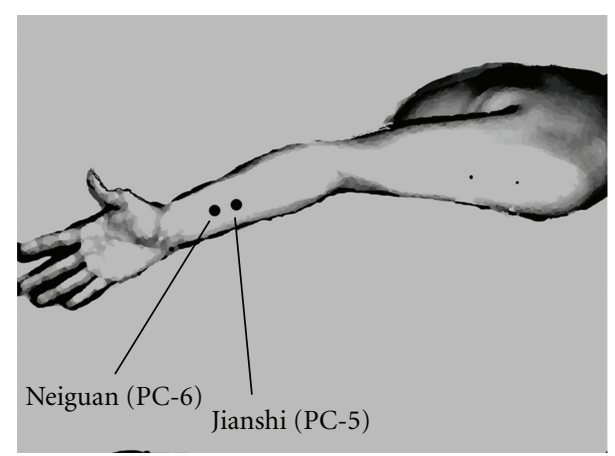

FIGURE 1: The locations of small-sized cutaneous electrode pads for transcutaneous electrical nerve stimulation.

Atropine of $0.5 \mathrm{mg}$ was given intravenously to treat bradycardia, defined as a decrease in heart rate to less than 50 beats $\min ^{-1}$.

Using empirical data from our daily clinical practice, the mean (SD) of the lowest SBP was 85 [9] after epidural injection of $10 \mathrm{~mL}$ of $2 \%$ lidocaine. Thus, a group size of at least 12 patients was needed to show a difference of 15 (SD 10) in the lowest SBP with a significant level of $0.05(\alpha=0.05)$ and a power of $80 \%(\beta=0.20)$. Data are expressed as median (range). Statistical analysis was performed using the Kruskal-Wallis test followed by Dunn's method for multiple comparisons. A $P<0.05$ value was considered to be significant.

\section{Results}

Demographic data and baseline measurements to wound closure time were comparable among the five groups (Table 1). Baseline systolic blood pressures (SBPs) were similar among these groups (Table 2).

The lowest SBP was significantly higher in the $40 \mathrm{~Hz}$ group compared to that of the control, $2 \mathrm{~Hz}$ and $20 \mathrm{~Hz}$ groups (the control, 84 (74-110) $\mathrm{mmHg}$; the $2 \mathrm{~Hz}, 96$ (62116) $\mathrm{mmHg}$; the $10 \mathrm{~Hz}, 100(68-110) \mathrm{mmHg}$; the $20 \mathrm{~Hz}$, 96 (64-115) mmHg; the $40 \mathrm{~Hz}, 104(75-140) \mathrm{mmHg}, P=$ $0.004)$ (Table 2). Significantly less patients experienced hypotension in the $40 \mathrm{~Hz}$ group (the control, $11(78 \%)$; the $2 \mathrm{~Hz}, 6$ (43\%); the $10 \mathrm{~Hz}, 5(38 \%)$; the $20 \mathrm{~Hz}, 5(38 \%)$; the $40 \mathrm{~Hz}, 1$ (8\%), $P=0.008)$. Two, one, and four patients experienced severe hypotension (SBP less than $70 \mathrm{mmHg}$ ) in the $2 \mathrm{~Hz}$, $10 \mathrm{~Hz}$, and $20 \mathrm{~Hz}$ groups, respectively. Less ephedrine was required to maintain arterial blood pressure in the $40 \mathrm{~Hz}$ group (the control, $8(0-16) \mathrm{mg}$; the $2 \mathrm{~Hz}, 0(0-20) \mathrm{mg}$; the $10 \mathrm{~Hz}$, 
TABle 2: Haemodynamic data and dose of ephedrine. Data are median (range) or number (percentage). SBP: systolic blood pressure. ${ }^{\dagger}$ : significantly different from the control group. ${ }^{*}$ : significantly different from the $40 \mathrm{~Hz}$ group.

\begin{tabular}{|c|c|c|c|c|c|c|}
\hline & Control $(n=14)$ & $2 \mathrm{~Hz}(n=14)$ & $10 \mathrm{~Hz}(n=13)$ & $20 \mathrm{~Hz}(n=13)$ & $40 \mathrm{~Hz}(n=13)$ & $P$ \\
\hline Intensity of TENS (mA) & - & $13(9-17)$ & $12(9-15)$ & $13(9-15)$ & $13(9-15)$ & 0.721 \\
\hline Baseline SBP (mmHg) & $130(104-150)$ & $135(115-145)$ & $130(110-145)$ & $130(114-145)$ & $132(116-158)$ & 0.994 \\
\hline Lowest SBP (mmHg) & $84(74-110) *$ & $96(62-116) *$ & $100(68-110)$ & $96(64-115)^{*}$ & $104(75-140)$ & 0.004 \\
\hline Baseline HR (beats $\min ^{-1}$ ) & $72(56-98)$ & $76(56-105)$ & $70(60-85)$ & $70(54-85)$ & $75(55-105)$ & 0.343 \\
\hline HR at lowest SBP (beats $\min ^{-1}$ ) & $62(45-80)$ & $64(40-76)$ & $61(44-86)$ & $55(45-75)$ & $65(50-95)$ & 0.522 \\
\hline Incidence of hypotension $(n)$ & $11(78 \%)$ & $6(43 \%)$ & $5(38 \%)$ & $5(38 \%)$ & $1(8 \%)^{\dagger}$ & 0.008 \\
\hline Ephedrine (mg) & $0(0-16)$ & $8(0-20)$ & $0(0-8)$ & $0(0-12)$ & $0(0-8)^{\dagger}$ & 0.013 \\
\hline
\end{tabular}

0 (0-8) $\mathrm{mg}$; the $20 \mathrm{~Hz}, 0(0-12) \mathrm{mg}$; the $40 \mathrm{~Hz}, 0$ (0-8) $\mathrm{mg}$, $P=0.013)$.

\section{Discussion}

The present study showed that a frequency of $40 \mathrm{~Hz}$ of TENS on the PC-5 and PC- 6 points significantly reduced the severity and incidence of hypotension after epidural anaesthesia in patients undergoing inguinal hernia repair, compared to frequencies of 2, 10, and $20 \mathrm{~Hz}$ of TENS on the two points.

Acupuncture, acupressure, and TENS on the traditional acupuncture points have been administered for peri-operative management [9-11]. Electroacupuncture at an acupuncture point affects haemodynamics and the sympathetic nervous system $[8,12,13]$. Electroacupuncture at the PC-5 increases stroke volume and cardiac output and furthermore reduces the severity of bleeding-induced hypotension $[5,6]$.

Since TENS was administered at the most intense tolerable electrical sensation in the present study, there is a possibility that TENS itself had some activating effects on the sympathetic nervous system [7]. While administering the same level of electrical stimulation, however, TENS at the specific frequency, $40 \mathrm{~Hz}$, significantly sustained blood pressure. Some studies showed that electroacupuncture on the PC-5 at $40 \mathrm{~Hz}$ enhances myocardial function and prevents bleeding-induced hypotension $[5,6]$, which are consistent with the present study. In contrast, electoacupuncture at 2$4 \mathrm{~Hz}$ suppresses cardiovascular sympathetic reactions [3, 4]. In fact, 2, 10, and $20 \mathrm{~Hz}$ stimuli induced severe hypotension in some patients in the present study. A stimulation of somatic afferent fibres at $5 \mathrm{~Hz}$ causes a depressor effect, while a stimulation of $40 \mathrm{~Hz}$ leads to a pressor effect [14]. Also, a study showed that stimulation of myelinated fibres alone or myelinated and unmyelinated fibres together leads to a depressor effect [15]. In contrast, stimulation of unmyelinated fibres alone causes a pressor effect. We thus speculate that $40 \mathrm{~Hz}$ stimulus might have provoked the activation of unmyelinated fibres, compared with 2,10 , and $20 \mathrm{~Hz}$ stimuli in the present study.

In conclusion, TENS on the PC-5 and PC-6 points reduced the severity and incidence of hypotension after epidural anaesthesia in patients undergoing inguinal hernia repair, depending on the stimulus frequency.

\section{References}

[1] K. Holte, N. B. Foss, C. Svensén, C. Lund, J. L. Madsen, and H. Kehlet, "Epidural anesthesia, hypotension, and changes in intravascular volume," Anesthesiology, vol. 100, no. 2, pp. 281286, 2004.

[2] M. Curatolo, P. Scaramozzino, F. S. Venuti, A. Orlando, and A. M. Zbinden, "Factors associated with hypotension and bradycardia after epidural blockade," Anesthesia \& Analgesia, vol. 83, no. 5, pp. 1033-1040, 1996.

[3] S. C. Tjen-A-Looi, P. Li, and J. C. Longhurst, "Midbrain vlPAG inhibits rVLM cardiovascular sympathoexcitatory responses during electroacupuncture," American Journal of Physiology, vol. 290, no. 6, pp. H2543-H2553, 2006.

[4] P. Li, S. C. Tjen-A-Looi, and J. C. Longhurst, "Excitatory projections from arcuate nucleus to ventrolateral periaqueductal gray in electroacupuncture inhibition of cardiovascular reflexes," American Journal of Physiology, vol. 290, no. 6, pp. H2535-H2542, 2006.

[5] Y. Syuu, H. Matsubara, T. Kiyooka et al., "Cardiovascular beneficial effects of electroacupuncture at Neiguan (PC-6) acupoint in anesthetized open-chest dog," The Japanese Journal of Physiology, vol. 51, no. 2, pp. 231-238, 2001.

[6] Y. Syuu, H. Matsubara, S. Hosogi, and H. Suga, "Pressor effect of electroacupuncture on hemorrhagic hypotension," American Journal of Physiology, vol. 285, no. 6, pp. R1446R1452, 2003.

[7] Y. C. Arai, N. Kato, M. Matsura et al., "Transcutaneous electrical nerve stimulation at the PC-5 and PC-6 acupoints reduced the severity of hypotension after spinal anaesthesia in patients undergoing Caesarean section," British Journal of Anaesthesia, vol. 100, no. 1, pp. 78-81, 2008.

[8] P. Li, O. Ayannusi, C. Reid, and J. C. Longhurst, "Inhibitory effect of electroacupuncture (EA) on the pressor response induced by exercise stress," Clinical Autonomic Research, vol. 14, no. 3, pp. 182-188, 2004.

[9] L. Chen, J. Tang, P. F. White et al., "The effect of location of transcutaneous electrical nerve stimulation on postoperative opioid analgesic requirement: acupoint versus nonacupoint stimulation," Anesthesia \& Analgesia, vol. 87, no. 5, pp. 11291134, 1998.

[10] E. Zárate, M. Mingus, P. F. White et al., "The use of transcutaneous acupoint electrical stimulation for preventing nausea and vomiting after laparoscopic surgery," Anesthesia \& Analgesia, vol. 92, no. 3, pp. 629-635, 2001.

[11] B. Wang, J. Tang, P. F. White et al., "Effect of the intensity of transcutaneous acupoint electrical stimulation on the postoperative analgesic requirement," Anesthesia \& Analgesia, vol. 85, no. 2, pp. 406-413, 1997. 
[12] E. Haker, H. Egekvist, and P. Bjerring, "Effect of sensory stimulation (acupuncture) on sympathetic and parasympathetic activities in healthy subjects," Journal of the Autonomic Nervous System, vol. 79, no. 1, pp. 52-59, 2000.

[13] Z. Li, C. Wang, A. F. Mak, and D. H. Chow, "Effects of acupuncture on heart rate variability in normal subjects under fatigue and non-fatigue state," European Journal of Applied Physiology, vol. 94, no. 5-6, pp. 633-640, 2005.

[14] D. L. Clement, C. L. Pelletier, and J. T. Shepherd, "Role of muscular contraction in the reflex vascular responses to stimulation of muscle afferents in the dog," Circulation Research, vol. 33, no. 4, pp. 386-392, 1973.

[15] B. Johansson, "Circulatory responses to stimulation of somatic afferents with special reference to depressor effects from muscle nerves," Acta physiologica Scandinavica. Supplementum, vol. 198, pp. 1-91, 1962. 


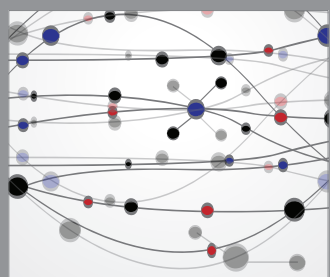

The Scientific World Journal
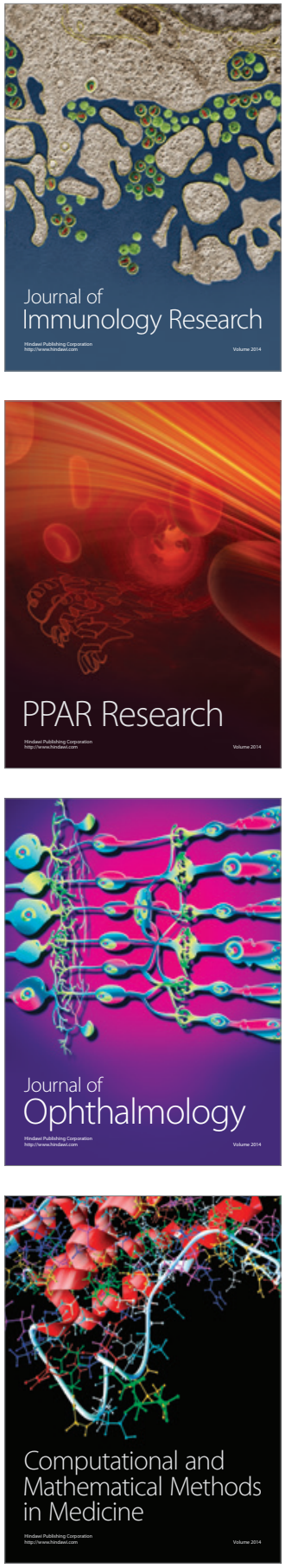

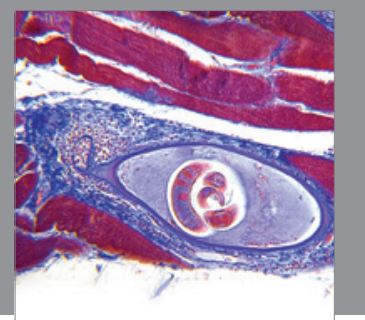

Gastroenterology

Research and Practice
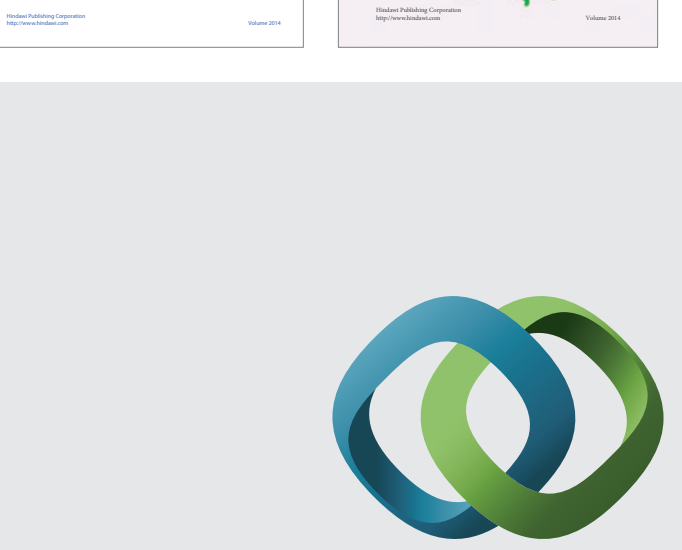

\section{Hindawi}

Submit your manuscripts at

http://www.hindawi.com
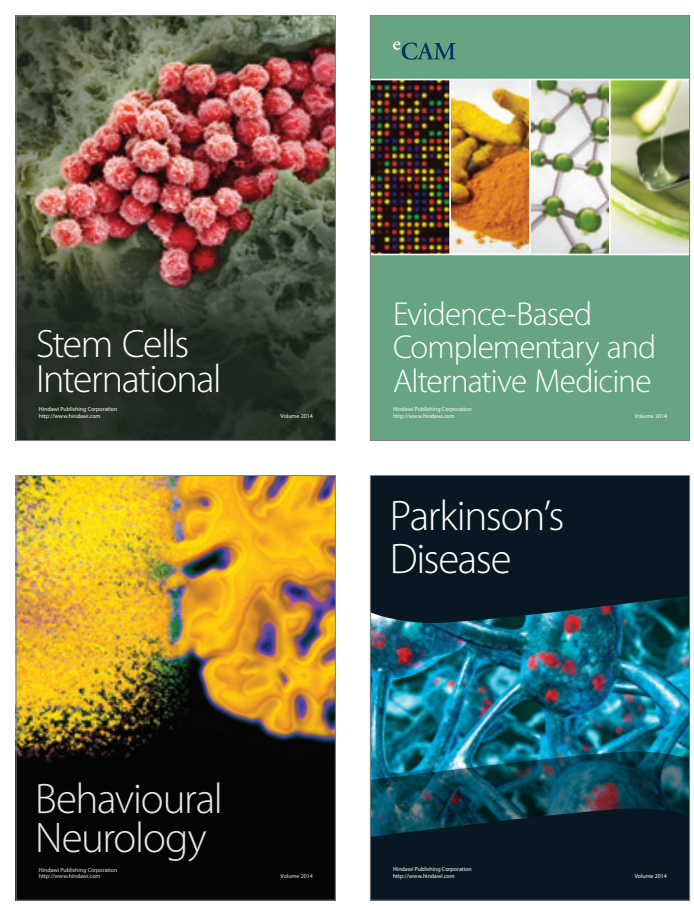

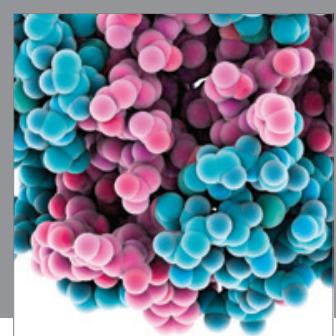

Journal of
Diabetes Research

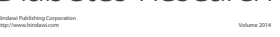

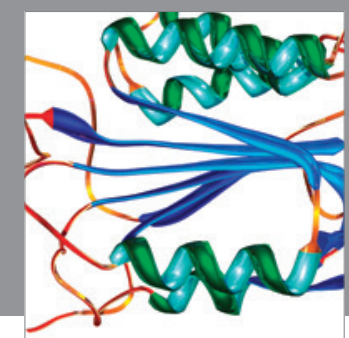

Disease Markers
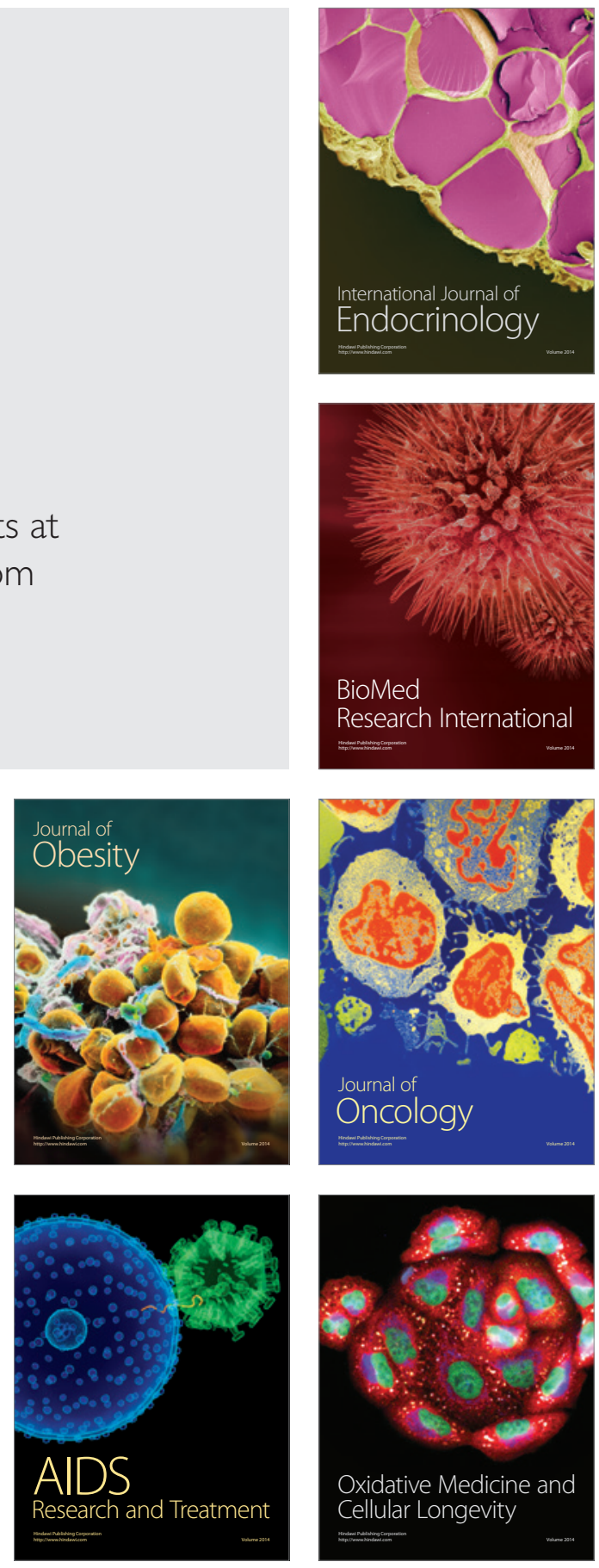